\title{
Design of A Problem Resolution Knowledge based System for Computer Diagnosis, Repair and Maintenance
}

\author{
Ajiteru S. O. ${ }^{1}$, Oluwasogo S. A. ${ }^{1}$ and Ejigah O. O. ${ }^{1}$ \\ ${ }^{1}$ ICT Centre, Federal Polytechnic Offa, Offa, Kwara State, \\ Nigeria.
}

\begin{abstract}
This paper presents the design of a problem resolution knowledge based system for computer diagnosis, repair and maintenance. The research work focuses on knowledge based design and how to make it speed up computer diagnosis, repair and maintenance by making use of a centralized database as the backend where knowledge resides and designed HTML form as front end where users interact for knowledge acquisition and problem resolution. Computer Engineers, Technicians, users can quickly tap knowledge and make use of it for a timely problem resolution. The objectives include building an integrated knowledge based system where knowledge of many computer experts comes together for references, increasing speed in computer problems diagnosis and resolution; enhance problem solving skills of less experienced staff or users when there is no senior expert around. The design is achieved by making use of PHP, MySQL, Apache, Dreamweaver, and HTML as design tools.
\end{abstract}

Keyword: Problem, resolution, design, database, form, knowledge base

\section{INTRODUCTION}

Knowledge-Based System (KBS) is one of the major family members of the Artificial Intelligence (AI) group. KBS can act as an expert on demand without wasting time, anytime and anywhere. KBS can save money by leveraging expert, allowing users to function at higher level and promoting consistency. One may consider the KBS as productive tool, having knowledge of more than one expert for long period of time. In fact, a KBS is a computer based system, which uses and generates knowledge from data, information and knowledge.

(Sajja \& Akerkar 2010) Human brain can store several thousand folds of world's knowledge, still it is said that human brain is not fully utilized. Advances in human knowledge are tied directly to the ability to analyze to form information, process it into knowledge and communicate it to others. The human brain has approximately 1011 nerve cells called biological neurons. It is probably the most complex and least understood part of the human body. It is continuously thinking in declarative and procedural way for problem solving. But till today it is a mystery that how does the human mind work. This new millennium brought us an opportunity to attack all such questions with the help of new knowledge, new tools and new resources.

(Darek and Jain 1991) Development of systems that make use of knowledge, wisdom and intelligence is a step towards meeting this challenge. The ability of the intelligent systems to capture and redistribute expertise has significant implications on development of a nation, commodity or population. Such systems allow documentation of one or more expert knowledge and utilize the knowledge for problem solving in cost effective way. It allows for, in a controlled manner, the import of expertise in various areas that the nation lacks, the export of knowledge relating to domestic areas of expertise, and the duplication and redistribution of scarce knowledge in a cost effective manner.

(Akerkar \& Sajja 2009) Thus areas of expertise that the selected domain/region/nation is deficient in or possesses exclusively are potential candidates of the knowledgebased systems. Though synthesized information is a key element for success, in many businesses it is a missing piece. A significant amount of Gross National Product (GNP) is invested in transferring knowledge through education and training. The AI systems effectively distribute the scarce resources for the development process. The Knowledge-Based Systems (KBS), which are a step towards an intelligent system, can be justified when a few individuals have the majority of the knowledge.

The needs to represent knowledge of human experts captured from knowledge acquisition interface, store in a database or knowledge base in order to solve problems that normally require human expertise has drawn our attention to contribute in the field of artificial intelligence. The research is designed in a way to represent knowledge and create an explained solution.

\section{AIMS AND OBJECTIVES OF THE STUDY}

The aim of research into Knowledge-Based Intelligent Engineering is to develop systems that replicate the analytical, problem solving and learning capabilities of the brain. These systems bring the benefits of knowledge and intelligence to the solution of complex problems.

The objectives of the research include:

1. To design a knowledge-based intelligent system

2. To bring together knowledge of many experts in computer knowledge domain

3. To speed up computer problems diagnosis and resolution

4. To enhance problem solving skills of less experienced staff or users when there is no senior expert around

5. To reduce cost of flying an expert when the need arise 


\section{RESEARCH METHOLODOLOGY}

This paper used statistical method of transcription from records to gather information about knowledge engineering. Direct Observation method was also used to study the process currently in place. The design is carried out using Open Source technology such as PHP, Mysql, Apache and Dreamweaver to design and implement a knowledge based system.

\section{KNOWLEDGE BASED SYSTEM AS A DIAGNOSTIC TOOL}

- Diagnosis - Provides identification about a problem given a set of symptoms or malfunctions.

- Interpretation - Provides an understanding of a situation from available information.
- Design - Develops configurations that satisfy constraints of the problem.

- Monitoring - Checks performance \& flags inconsistencies

- Control - Collects \& evaluate evidence and from opinions on that evidence.

- Debugging - Identifies and prescribes remedies for malfunctions.

COMPONENTS OF KNOWLEDGE BASED SYSTEM

$>$ Knowledge base (facts)

$>$ Inference Engine

Dnowledge Acquisition Interface

User Interface

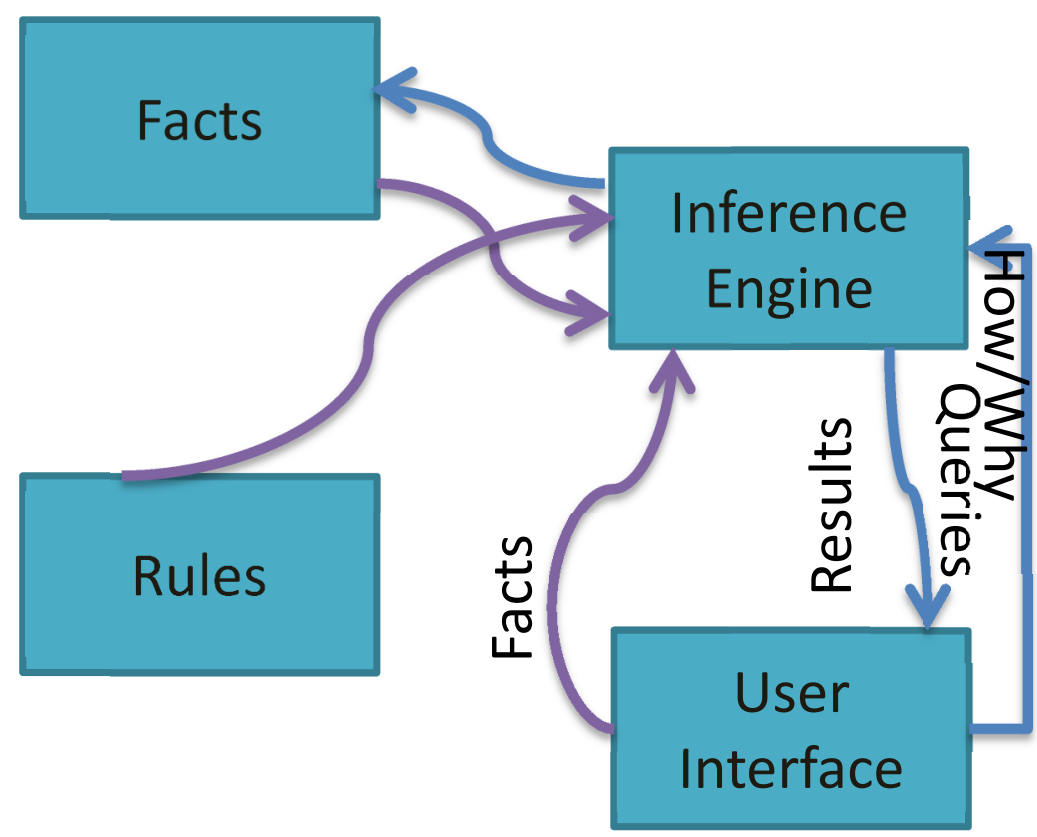

Figure 1: Components of KBS

THE DESIGN STRUCURE OF KBS

The development of Knowledge based always involved the knowledge

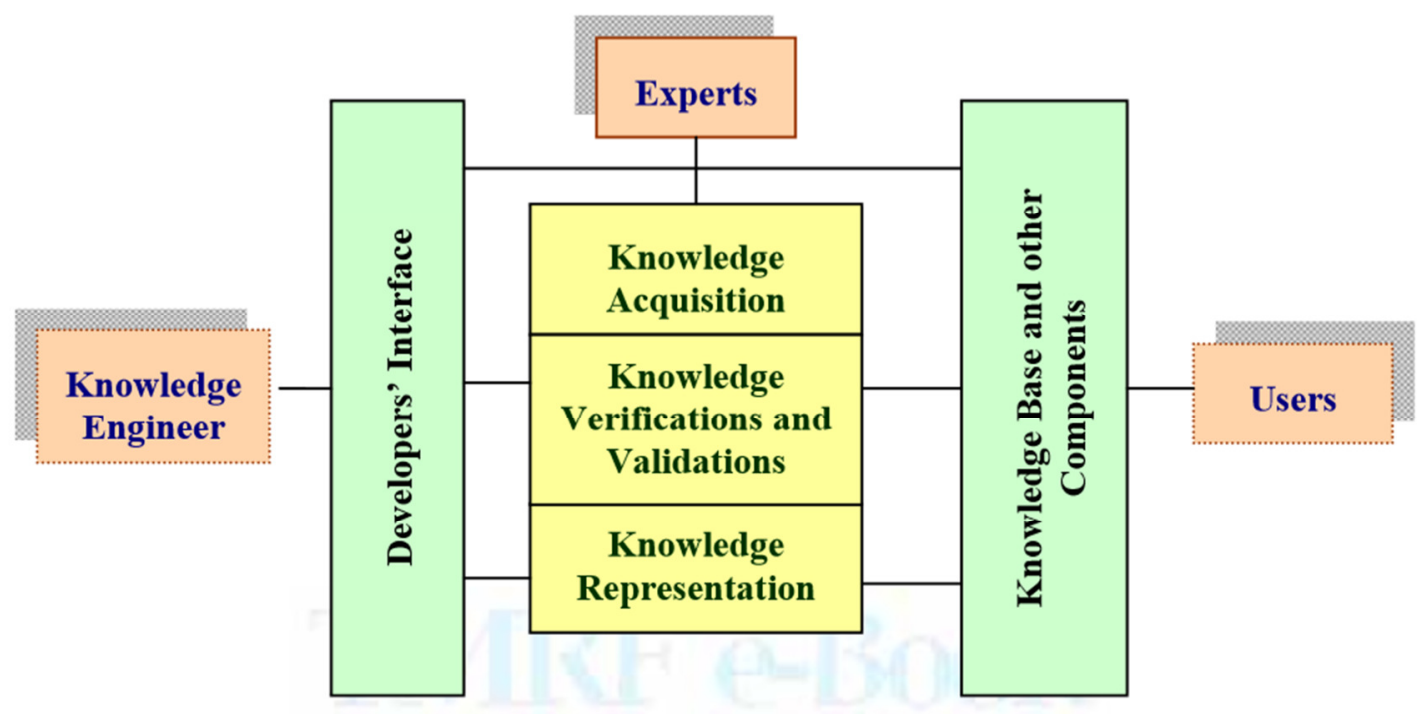

Figure 2: The Input Design Structure of KBS 
Knowledge Engineer: A knowledge engineer is a computer scientist who knows how to design and implement programs that incorporate artificial intelligence techniques.

Expert: A domain expert is an individual who has significant expertise in the domain of the expert system being developed.

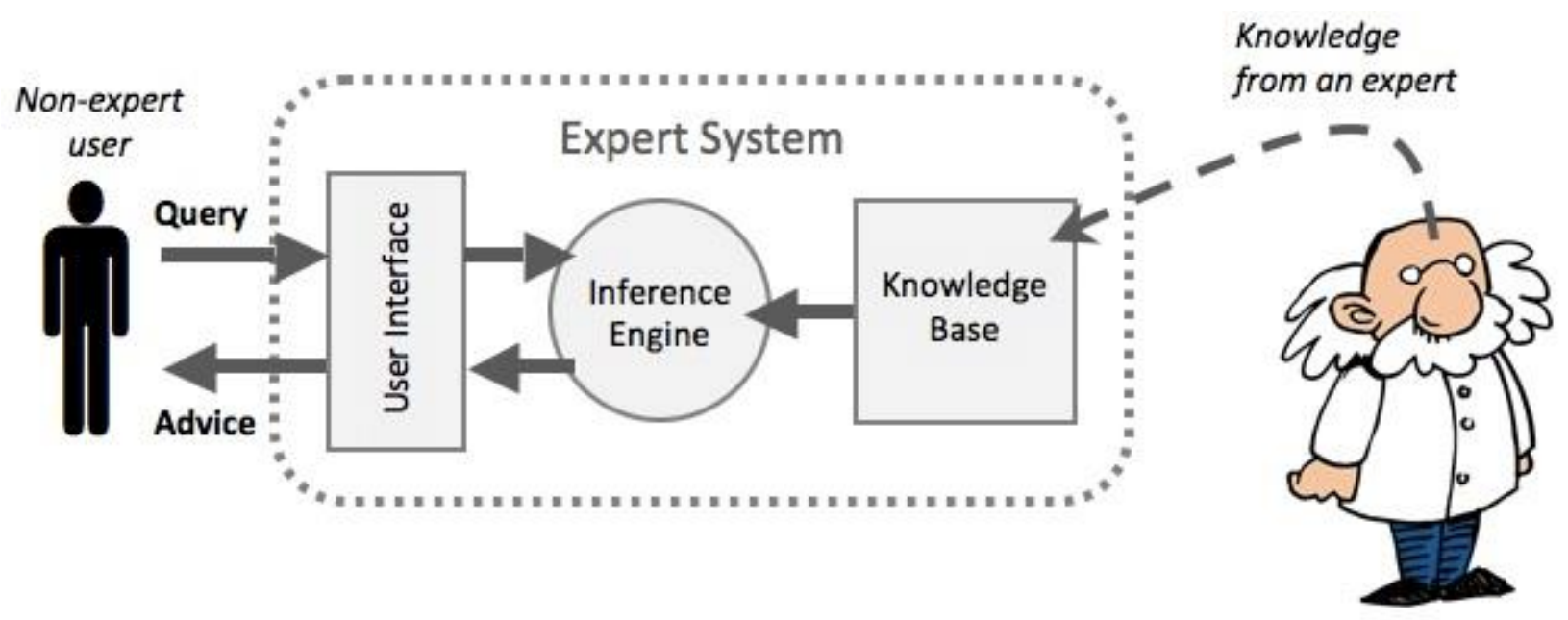

Figure 3: The Output Design Strucure of KBS

\section{DESIGN TOOLS}

- Server Technology: APACHE

- Database: MySQL

- Markup Language: HTML

- Development Environment: Dreamweaver 8

- Scripting Language: PHP

THE INPUT DESIGN

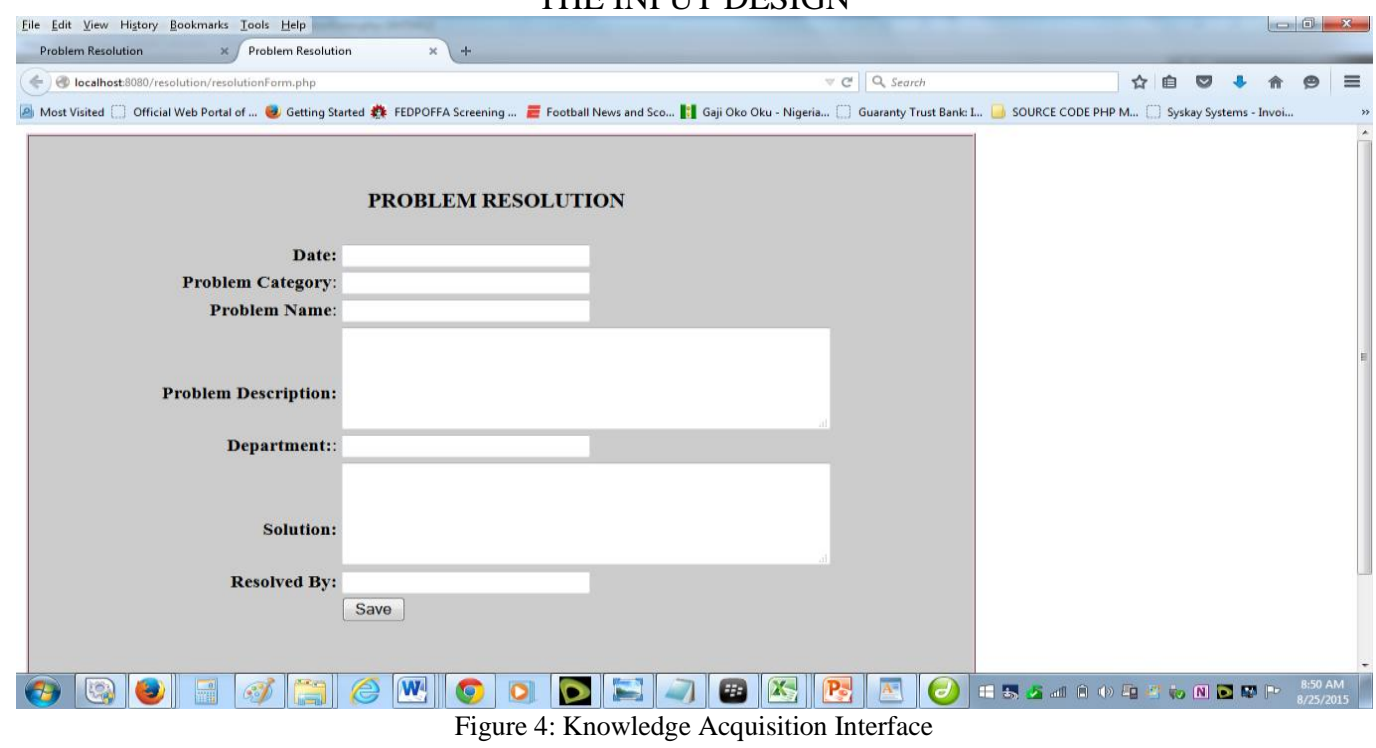



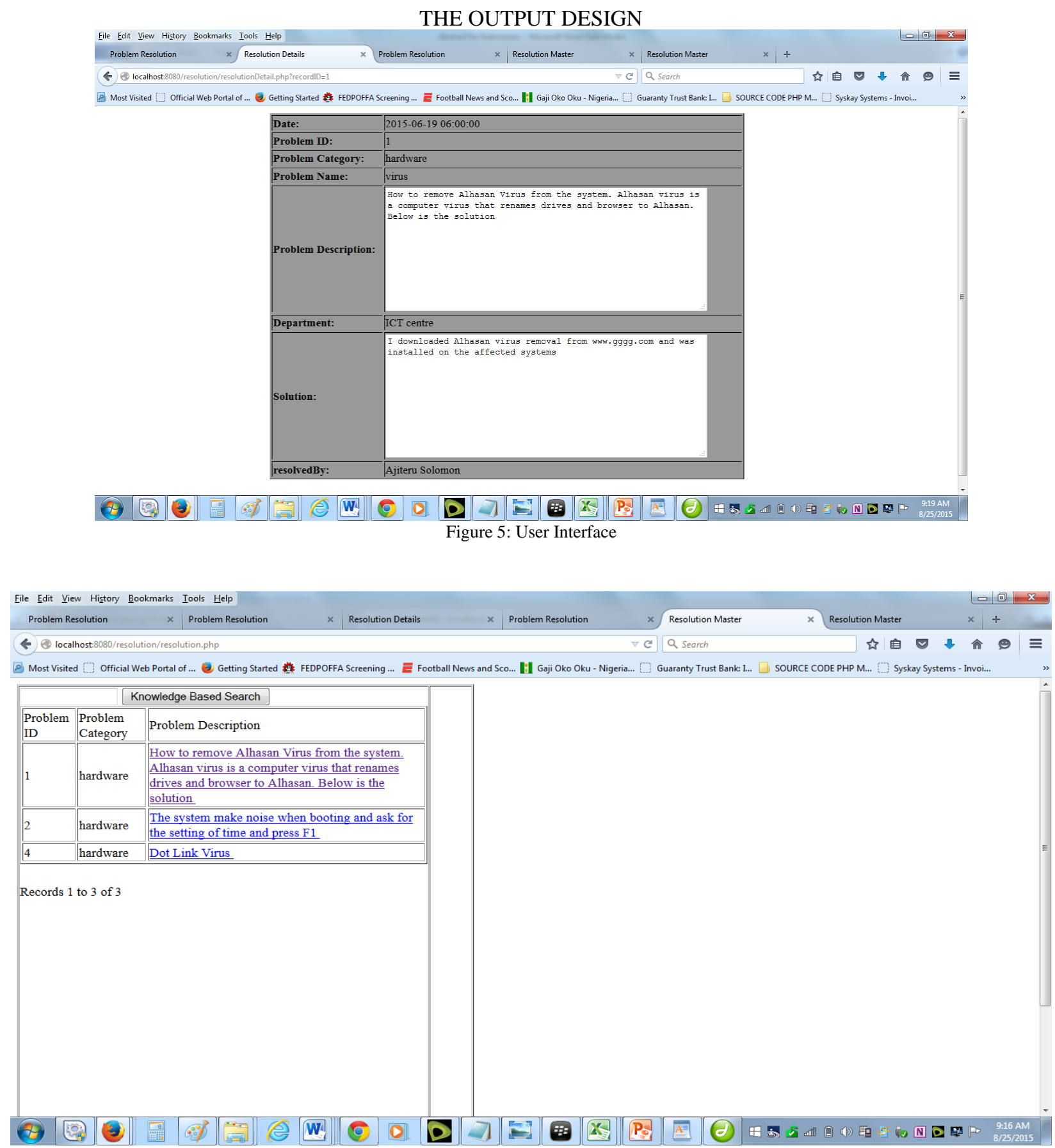

Figure 6: Knowledge Based Search

\section{CONCLUSION}

This paper has discussed and designed a computer program that performs at high levels of competence as knowledgebased intelligent system. The paper applied artificial intelligence/expert system techniques in problem solving processes to achieve the software designed. It incorporates a store (database) of expert knowledge with couplings and linkages designed to facilitate its retrieval in response to specific queries, or to transfer expertise within the computer domain of hardware and software engineering.

\section{RECOMMENDATION}

Knowledge based system has many advantages and it is more useful in many situations than the trditional computer based information systems. Some major situations include: When expert is not available, when expertise is to be stored for future use or when expertise is to be cloned or multiplied, when intelligent assistance and/or training are required for the decision making for problem solving, when more than one experts' knowledge have to be grouped at one platform. As a result of these, it is therefore strongly recommended that knowledge based system should be embraced in design and usage. The knowledge based 
system is not limited to computer domain alone; it should be utilized by all sciences and engineering domain.

\section{REFERENCES}

[1] Akerkar, R.A. and Sajja, P.S. (2009). Knowledge-based systems: Jones \& Bartlett Publishers, Sudbury, MA, USA.

[2] Alty J.L. (1989). Expert system building tools. In: eds. Guida, G. and Tasso, C. Topics in Expert System Design: Methodologies and Tools: North-Holland, Amsterdam.

[3] Derek, N. and Jain, H. (1991). The relevance of ES technology for India: A Transborder Perspective, CSI Digest, 3(1):68 Pearl, J. 1984.

[4] McCarthy, J. 1960. Recursive functions of symbolic expressions and their computation by machine. Communications of the ACM, 3(4): 184-195.

[5] Kowalski, R.A. 1988. The early years of logic programming, Communications of the ACM, 31(1): 38-43.

[6] Pearl, J. 1984. Heuristic-intelligent search strategies for computer problem solving: Addison Wesley Publishing Company.

[7] Robertson, S. \& Kingston, J. 1997. Selecting a KBS tool using a knowledge-based system, AIAI-TR-214. Available at http://www.aiai.ed.ac.uk/project/ftp/documents/1997/97paces97-select-kbs-tool.ps

[8] Sajja \& Akerkar (2010). Advanced Knowledge Based Systems:Model, Applications \& Research Vol. 1, pp 1-11

[9] Tuthhill, S. and Levy, S. 1991.Knowledge-based systems: A managers perspective: TAB Professional \& Reference Books.

[10] http://www.kesinternational.org/journal/topics.php

$\underline{\text { Date }}$ Accessed: 22/06/2015

[11] http://www.businessdictionary.com/definition/knowledgebased-system.html Date Accessed: 02/06/2015 